Self-harm wounds - assessment and management

'at a glance clinical review article for commissioned series'.

This article will:

- Provide clinical guidance on self-harm wound assessment

- Provide an awareness of the complications of wound healing in self-harm wounds

- Provide guidance for management of self-harm wounds

\title{
Self-harm
}

Self-harm (SH) is the collective term for self-poisoning, self-inflected injury or self-mutilation irrespective of the apparent purpose of the act (NICE, 2013). The act of SH tends to be without suicidal intent and is followed by a sense of relief and relaxation. $\mathrm{SH}$ can be a coping mechanism, often as a result of trauma, psychological illness, abuse, a deep-seated sense of powerlessness or negative feelings (such as anger, guilt, frustration, hopelessness and self-hatred; MIND, 2020). These overwhelming emotional feelings are converted into a visible, physical wound, which the individual can find easier to deal with (Sutton, 2007). The UK has the highest recorded $\mathrm{SH}$ rate of all European countries (Mental Health Foundation, 2017). In 2019 the prevalence of non-suicidal self-harm has nearly tripled in England over the past 10 years (Mayor, 2019). Early figures from the Covid-19 pandemic demonstrated a 38\% decreased in rates in reported self-harm in April 2020 (Kapur et al., 2020) with 2-4\% of people in the UK indicating that they have self-harmed in the previous week (Kapur et al., 2020). Yet, recent news reports suggest that the pandemic has had a deep impact on the younger generation with greater numbers of children presenting at A\&E after self-harming or 
taking over doses. Females have a higher prevalence rate of $\mathrm{SH}$ yet males may display other behaviours not generally categorised as SH such as punching walls (MIND, 2020). Other high risk groups include the under 25's who have experienced some form of trauma, sexual abuse, drug and alcohol dependency or those with poor self-efficacy and coping skills (NICE 2011b).

A wide range of implements can be used to cause self-harm and often the thighs, stomach, lower and upper arms are common areas for injury and preferable for concealment (Sutton, 2007; MIND, 2013).

Figure 1

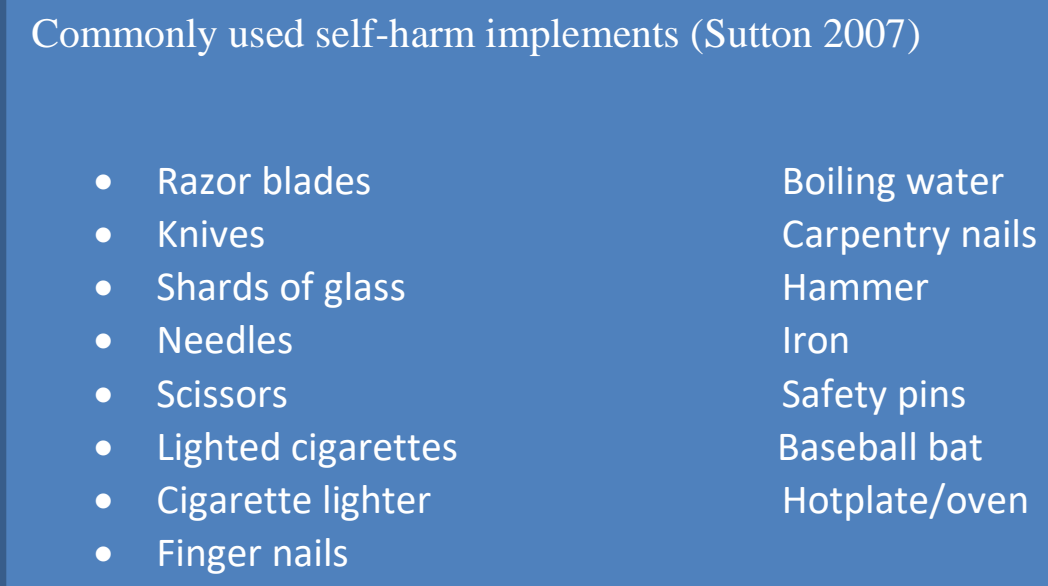

$\mathrm{SH}$ can be defined in both compulsive and impulsive behaviours. Compulsive $\mathrm{SH}$ involves a strong urge or craving to inflict injury. This form of SH involves detailed planning of the injury and following aftercare. Initial relief is obtained from injury but often compulsion reoccurs resulting in reopening of the soft tissue and disruption in healing (Hunt, 2017). Impulsive SH is spontaneous with little planning or aftercare. This can be associated with alcohol, drug taking and psychological issues. Presentation of these wounds often includes infection, deep 
skin damage which require suturing or surgical intervention (Kilroy-Findley and Bateman, 2016).

\section{The skin}

The skin is the largest organ in the body and there are two main divisions; the outer epidermis and deeper dermis. The epidermis is made up of five layers of cells. The dermis is divided into two main layers (see figure 1: layers of the skin). Editor, please include a diagram of the skin. The functions of the skin are as follows:

- Barrier and immune defence

- Touch and sense

- Excretion

- Thermoregulation

- Nutrient store

- Synthesis of vitamins

- Physical protection for organs and underlying structure

- Water-resistant barrier

(Blows, 2018)

A break in the skin caused by a wound means that these functions and barriers are temporarily lost resulting in a disruption of homeostasis. $\mathrm{SH}$ can increase the risk of: complications to the skin, soft tissue damage, scarring, non-healing wounds and infection (Hunt, 2017).

\section{Assessment}


A holistic wound assessment is essential to identify causative and contributory factors of wounding (Mitchell, 2020). Accurate and timely wound assessment is the underpinning of effective clinical decision making, agreeing on appropriate patient-centred goals and referral to a mental health team, social worker or appropriate allied worker is essential for holistic support (Hunt, 2017; Mitchell, 2020). Self-inflicted wounds are often 'bizarre looking' (Benbow, 2011). They may present in a variety of forms such as blisters, purpura, oedema,

erythema or nodules and can often be misleading which leads to misdiagnosis (Benbow, 2011).

\section{Assess the patient}

Assessment involves gathering and interpreting information about the patient. A holistic assessment should include specific questions relating to the patients' health and wellbeing. This will provide clinicians with a strong foundation to manage the patients' skin and wound identifying biological, psychological and sociological factors that may delay wound healing (Mitchell, 2020). It is essential to develop a positive therapeutic relationship with any individual who has self-harmed to gain trust, encourage adherence to wound treatment and management strategies and establish the underlying reason for SH (Wright, 2010). Initially patients traditionally tend to care for their own SH wounds with household materials such as towels, flannels and basic first aid kits (Kildroy-Findley and Bateman, 2016.

- Ask the patients age - the highest rate of self-harm is reported in women aged 16-24 (Mental Health Foundation, 2016) 
- Assess risk - individuals who self-harm should be assessed for risk of further injurious behaviour as well as potential suicide (Ousey \& Ousey, 2012). Assessment should identify the patient's mental capacity and willingness to undergo a further psychological assessment. Refer to the local mental health service.

- Assess for contributing factors to the act of self-harm for example alcohol or drug misuse. It may be necessary to refer to local alcohol and drugs services.

- Past medical history including any previous wounds - this is particularly relevant for recurrent self-harm wounds

- Medical and family background. Include questions about any potential stressors in the patients family dynamics or personal relationships. This may warrant referral to the psychological therapy team.

- Ask the patient about any allergies, previous investigations or surgical procedures.

- Ask the patient if they have any chronic medical conditions

- Obtain a list of medications

- Assess the patients nutritional status and any supportive therapies or dietary supplements. The Malnutrition Universal Screening Tool (MUST) (BAPEN, 2018) is useful for nutritional screening

- Lifestyle choices, current activities, smoking

- Socioeconomic circumstances, employment, occupation

\section{Management of the wound}

- Confirm the patients identify, explain and discuss the full procedure and obtain consent

- Ask the patient if they have any allergies 
- Wash hands and put on aprons and gloves

- If the patient presents after initial wounding immediate action may be required to control the bleeding, address shock from hypovolaemia (Hill \& Mitchell, 2020), restore blood perfusion by removing ligatures or stabilising a puncture wound (Ousey \& Ousey, 2012).

- Review the history and duration of the wound. This should include how the wound was caused including any instruments used and type of wound. Repeated injury and inflammation can result in elevated, thick or nodular hypertrophic scars (Benbow, 2011)

- Review the level of tissue injury - does the wound involve the epidermis, dermis, fat, fascia, muscle, tendon and/or bone? Document findings.

- Wound site - document the location of the wound on a body map and the care plan

- Wound size - wound size should be measured and documented in the patients' notes on each dressing change.

- Wound depth - if necessary take a measurement of the wound depth using a sterile swab. This procedure should only be carried out by qualified practitioners who are familiar with the anatomy and structures in close proximity of the wound.

- Colour and type of wound bed tissue - document the colour of the wound bed and percentage of types of tissue. Colour of tissue is used to distinguish between viable and non-viable tissue (Atkin et al., 2019).

- Assess for infection. Identification of how the wound was caused and how long the wound has been present will give an indication of the risk of infection. This would be a good opportunity to explain infection risks to the patient, classical signs and 
symptoms of infection. Advise the patient that localized heat or pain and changes in body temperature may indicate a sign of infection.

- Assess the presence or absence of pain. Ask the patient if they are experiencing any pain and does the pain affect quality of life? Use of a valid pain tool for assessment (Mitchell, 2020).

- Assess the peri wound for the presence of conditions such as eczema, excoriation, maceration and moisture associated skin damage (Mitchell \& Hill, 2020)

- Clean the wound - in most cases tap water can be used for wound irrigation (Peate \& Stephens, 2019) if the presence of infection is suspected or the patients general health is compromised sterile saline is advised (Peate \& Stephens, 2019). Avoid using gauze swabs for irrigation; these cause trauma and pain on wound contact. The gauze swabs spread the bacteria around the wound without removal. Irrigating fluid should simply be poured over the wound (Peate \& Stephens, 2019).

- For superficial uncomplicated injuries for $5 \mathrm{~cm}$ or less in length consider using tissue adhesive or skin closure strips.

- Assess the patients' knowledge of health and level of health literacy. The educational needs of the patient must be evaluated on an individual basis (Mitchell, 2020)

- Discuss the use of a 'rescue pack' - in general practice rescue packs are used to improve patients ability to manage their wounds pre and post injury. The contents of the pack are simple and easy for patients to understand. The pack should highlight how to use and replace the products/dressings and a list of 'red flags' when to seek clinical advice.

Example rescue pack adapted from Hunt (2017) 


\begin{tabular}{|c|c|}
\hline Product & Purpose \\
\hline Sterile dressing pack with gloves and tray & $\begin{array}{l}\text { Used for a clean procedure, skin and wound } \\
\text { cleansing }\end{array}$ \\
\hline Gauze & Used to clean and mop up body fluids \\
\hline $\begin{array}{l}\text { Antiseptic antimicrobial product e.g. } \\
\text { irrigator, gel, wash or wipe }\end{array}$ & $\begin{array}{l}\text { Used to clean hands prior to the procedure } \\
\text { and clean the wound to reduce infection }\end{array}$ \\
\hline $\begin{array}{l}\text { Topical secondary dressing. This should be } \\
\text { an atraumatic dressing absorbent for low to } \\
\text { moderate exudate or blood. }\end{array}$ & $\begin{array}{l}\text { Non-adhesive dressing to keep the wound } \\
\text { clean and dry and prevent infection. }\end{array}$ \\
\hline $\begin{array}{l}\text { Antimicrobial skin wash (For example } \\
\text { Octenisan wash, Dermal or over the counter } \\
\text { products) }\end{array}$ & $\begin{array}{l}\text { Suitable for superficial scratches, subdermal } \\
\text { lacerations, cuts and abrasions }\end{array}$ \\
\hline $\begin{array}{l}\text { Barrier product (For example Cutimed } \\
\text { protect cream, Cavilon or other barrier } \\
\text { products) }\end{array}$ & $\begin{array}{l}\text { Protection for the surrounding skin and soft } \\
\text { tissue especially if there is bleeding or } \\
\text { moisture damage. }\end{array}$ \\
\hline $\begin{array}{l}\text { Microbial binding dressing (Leukomed, } \\
\text { Cutimed Sorbact) }\end{array}$ & $\begin{array}{l}\text { Suitable for infected wounds, deep infected } \\
\text { tissue following debridement, or deep } \\
\text { subcutaneous fat or muscle injury post } \\
\text { suturing. }\end{array}$ \\
\hline $\begin{array}{l}\text { Soft silicone dressing (For example Cuticell } \\
\text { contact) }\end{array}$ & Suitable for first and second degree burns \\
\hline
\end{tabular}




\begin{tabular}{|l|l|}
\hline A silicone foam dressing (Cutimed Siltec) or & Suitable for heavily exuding wounds \\
super absorbent dressing (For example & \\
\hline Patient information leaflets & Including product information, 'reg flags' for \\
& patients to monitor and seek advice (e.g. \\
& increased pain or temperature, discharge) \\
\hline
\end{tabular}

NB Dressing choice may be dependent on local wound formulary

- Give guidance and information around scarring for example oils, lotions and creams to moisturise healed skin and scar tissue. Pressure to the skin surface can flatten and soften scar tissue (this should be avoided if this causes discomfort), massage therapy and static or dynamic splints (Monstrey et al., 2013; Benbow, 2011) Medical invasive procedures may be suggested by healthcare professionals if indicated.

- Discuss self-care and provide education. Give the patient reassurance, confidence and encourage ownership with their self-care pathway (Hunt, 2017). Provide contact information for relevant services and ensure that replacement rescue pack processes are in place (Hunt, 2017).

\section{Conclusion}

The management of patients who $\mathrm{SH}$ and $\mathrm{SH}$ wounds requires time, patience, good communication and listening skills and a non-judgemental holistic approach. It is important that $\mathrm{SH}$ wounds are appropriately assessed and treatments and interventions are agreed between the healthcare professional and the patient. Healthcare practitioners must 
empower patients take ownership and responsibility and provide education to reduce serious injury, infection, scarring and attendance to urgent services.

\section{Reference List:}

Atkin L, Bućko Z, Conde Montero E, Cutting K, Moffatt C, Probst A, Romanelli M, Schultz GS, Tettelbach W. Implementing TIMERS: the race against hard-to-heal wounds. J Wound Care 2019; 28(3 Suppl 3):S1-S49

Benbow. M, Deacon. M, (2011) Helping people who self-harm care for their wounds. Mental Health Practice Vol 14, No 6

Blows, W. T. (2018) The biological basis of clinical observations. Routledge OXON. Cooper, R. (2010) How to... Ten top tips for taking a wound swab Wounds International Vol 1 , Issue 3

Hill. B, Mitchell. A, (2020) Hypovolemic shock. British Journal of Nursing. Vol 29 (10)

Hunt. S (2017) Management of self-harm wounds made easy. London: Wounds UK. Vol 13 (4) Available from www.wounds-uk.com

Kapur. N, Clements. C, Appleby. L, Hawton, K. Steeg. S, Waters. K, Webb. R (2021) Effects of the COVID-19 pandemic on self-harm. The Lancet. Vol 8 (2)

Kilroy-Findley. A, Bateman. SD, 2016 The psychology of self-harm and self-injury: does the wound management differ? Wounds UK 12(4) 88-94

National Institute for Clinical Excellence (2013) Self-harm, Quality standard (QS34) Accessed at https://www.nice.org.uk/guidance/qs34

National Institute for Clinical Excellence (2011b) Self-harm longer term management, costing report, NICE, London 
Mayor, S. (2019)Major rise in non-suicidal self-harm in England, study shows British Medical Journal 365 doi: https://doi.org/10.1136/bmj.14058 Accessed on 10/02/21

Mental Health Foundation (2017) Self-harm. Accessed at https://www.mentalhealth.org.uk/a-to-z/s/self-harm Accessed on 10/2/21

Mental Health Foundation (2016) Fundamental Facts About Mental Health. Accessed at https://www.mentalhealth.org.uk/sites/default/files/fundamental-facts-about-mental-health2016.pdf Accessed on 10/02/21

Mitchell. A (2020) Assessment of wounds in adults. British Journal of Nursing Vol 29 (20) Tissue viability supplement

Mitchell. A, Hill. B (2020) Moisture Associated skin damage: an overview of its diagnosis and management. British Journal of community Nursing. Vol 25 (3)

Mind (2021) Self-harm Accessed at https://www.mind.org.uk/information-support/types-ofmental-health-problems/self-harm/about-self-harm/ Accessed on 10/2/21

Monstrey. S, Middlekoop. E, Jeron Vranckx. J, Bassetto. F. Ziegler. U, Meaume. S, Teot. L, (2013) Updated Scar Management Practical Guideliens: Non-invasive and invasive measures. Journal of plastic, Reconstructive and Aesthetic Surgey 67, 1017-1025

Ousey C, Ousey K (2012) Management of self-harm wounds. Nursing Standard. 27, 9, 58-66.

Peate, I. and Stephens, M., 2019. Wound Care At A Glance. 2nd ed. Wiley-Blackwell. Chichester. burden of chronic wounds in the UK. Nursing Times 104(3): 44-5.

Sutton. J (2007) Healing the hurt within, understanding self-injury and self-harm and heal the emotional wounds, $3^{\text {rd }}$ edition, How to books, Oxford, UK

Wright KM (2010) Therapeutic relationship: developing a new understanding for nurses and care workers within an eating disorder unit. International Journal of Mental Health Nursing. 19, 3, 154-161. 